\title{
Condición y perspectivas de la meliponicultura en comunidades mayas de la reserva de la biósfera Los Petenes, Campeche, México
}

\author{
Condition and Perspectives of Meliponiculture \\ in Mayan Communities at Los Petenes Biosphere Reserve \\ in Campeche, Mexico
}

\author{
Lucio Alberto Pat Fernández \\ El Colegio de la Frontera Sur \\ Francisco Anguebes Franceschi \\ Universidad Autónoma del Carmen \\ Juan Manuel Pat Fernández \\ Pablo Hernández Bahena \\ Rodimiro Ramos Reyes \\ El Colegio de la Frontera Sur
}

\begin{abstract}
Resumen: La cría de la abeja sin aguijón ko'olel kaab (Melipona beecheii) es una actividad ancestral en vías de desaparición en la reserva Los Petenes, Campeche. Por su importancia para la estrategia de vida familiar en el área natural protegida y para procurar la conservación de la diversidad de especies de abejas nativas, se planteó el estudio de la situación y las perspectivas de la meliponicultura en dicha área. Se usaron encuestas semiestructuradas, entrevistas a informantes clave y observación participante. Los resultados muestran que solo seis de las 17 comunidades manejan la abeja ko'olel kaab y que los meliponicultores están constituidos mayoritariamente por hombres de edad avanzada con débil organización para comerciar la miel. Sin embargo, la perspectiva de la meliponicultura es alentadora, porque se ubica en un área natural protegida y el conocimiento y el manejo tradicional aún persisten en algunas familias mayas que producen miel para uso medicinal y ceremonial. Además, el mercado y el valor cultural de la meliponicultura son factores que pueden contribuir a su rescate.
\end{abstract}

Palabras clave: Abejas nativas, estrategia familiar, producción y manejo, área natural protegida.

АвSTRACT: Raising stingless bee (Melipona beecheii), called ko'olel kaab by the Maya of Campeche in The Petenes Biosphere Reserve, Mexico, is an age-old practice which is in danger of disappearing. Given the importance of meliponiculture to families' life strategy in this protected natural area, as well as to conservation of the diversity of native bee species, this study aimed to evaluate the current state of meliponiculture in the area through semi-structured questionnaires, interviews and participant observation. Only six of the 17 communities in the study region were found to still 
manage ko'olel kaab bees, and most keepers of native bees are men over the age of 65 . Furthermore, the communities lack the ability to produce and market honey. However, points in favor of meliponiculture among the Maya people of Campeche are that it is being practiced in a protected natural area, that traditional knowledge persists, and that families still raise stingless bees using traditional management techniques to produce honey and other products for medicinal uses and ceremonial use. Increasing the market value of meliponiculture and fomenting appreciation for its cultural value may contribute to its recovery.

KEYworDs: Native bees, family strategy, beekeeping management, natural protected area.

RECEPCIÓN: 13 de septiembre de 2017.

ACEPTACIÓN: 6 de noviembre de 2017.

DOI: 10.19130/iifl.ecm.2018.52.939.

\section{Introducción}

La meliponicultura es una actividad cultural, económica y social que las comunidades mayas desarrollaron antes de la llegada de los colonizadores europeos, según hallazgos de vestigios arqueológicos en Mesoamérica fechados para el periodo Protoclásico (Calkins, 1974; Crane, 1992; Zralka et al., 2014). Los mayas vinculaban la cría de la abeja sin aguijón (Melipona beecheii), conocida localmente como ko'olel $k a a b,{ }^{1}$ a la tradición religiosa del dios abeja conocido como Ah Mucen Kaab, a quien representaron en códices y figuras en templos posclásicos de la península de Yucatán como lo señalan diversos autores (Calkins, 1974; Barceló y Roubik, 2013; Jones, 2013). Además, entre los mayas existe una tradición ancestral del uso de la miel de ko'olel kaab con fines medicinales, para la preparación de bebidas empleadas en ceremonias religiosas y para endulzar alimentos (Nárez, 1988; Terán y Rasmussen, 1994; Vit, Medina y Enríquez, 2004; Ocampo, 2013).

Entre los mayas peninsulares, la meliponicultura forma parte de una estrategia familiar de uso múltiple de los recursos naturales (Hernández, Levy y Bello, 1995; Toledo et al., 2008) que combina el autoabasto con el comercio. Es una actividad importante en la estrategia campesina maya por su valor de uso y de cambio. A pesar de que la miel de ko'olel kaab es muy valorada en el mercado y de que posee importantes propiedades alimenticias y medicinales (Vit, Medina y Enríquez, 2004), la cría de esta abeja se encuentra en peligro de desaparecer (Villanueva, Roubik y Colli, 2005).

El inicio de la disminución de la meliponicultura se asocia con la introducción de la abeja europea (Apis mellifera) en la región a principios del siglo pasado.

\footnotetext{
${ }^{1}$ La literatura sobre la meliponicultura en Yucatán y Quintana Roo identifica a la especie de abeja Melipona beecheii principalmente con el nombre maya de xunan kaab; sin embargo, en la reserva de Los Petenes la nombran como ko'olel kaab y algunas veces como p'ol kaab.
} 
Aprovechando las condiciones de alta demanda de miel en los mercados europeo y estadounidense en aquella época, algunos empresarios introdujeron esta especie en la península de Yucatán para la producción comercial. Posteriormente, la adoptaron diversos productores mayas de miel para tener otra fuente de ingreso familiar destinada a comprar alimentos que no producían, como maíz y frijol (Terán y Rasmussen, 1994), para el pago de servicios médicos (Güemes, Villanueva y Eaton, 2003) o de deudas contraídas. La sustitución parcial de la meliponicultura por la apicultura basada en la abeja europea se debió al mayor rendimiento de ésta y a que sus ciclos de producción y su calendario de trabajo son compatibles con el sistema de la milpa (Rosales y Rubio, 2010). Otros factores vinculados a la reducción de la meliponicultura en las comunidades de la Reserva y en otros sitios de la península son a) la pérdida del conocimiento del manejo tradicional de la abeja debido al poco interés de la población joven, que prefiere emigrar a las ciudades, como San Francisco de Campeche, Mérida o Cancún, en busca de empleos; b) las deficiencias en el manejo de plagas durante la cosecha y en la división de las colonias; c) las sequías y los huracanes que se presentan en la región, y d) la producción de carbón vegetal, que ha deforestado grandes superficies donde se ha expandido la agricultura y la ganadería.

Hoy en día la elevada demanda de miel y otros subproductos (cerumen, polen y propóleos) de la abeja ko'olel kaab en el mercado regional ha incrementado significativamente el precio de éstos. Por tal razón, está resurgiendo el interés de los productores en preservar la meliponicultura. No obstante, debido al desconocimiento de las condiciones de mercado de los productores, los principales beneficiarios son los intermediarios.

En el estado de Campeche se conoce la existencia milenaria de la meliponicultura. Sin embargo, no existe ningún estudio de cuántas familias conservan esta actividad, ni cuáles son en la actualidad sus condiciones socioeconómicas o las perspectivas de la meliponicultura en sus comunidades. No sabemos exactamente cómo realizan la cría y el manejo de la abeja, cuáles son las limitantes y potencialidades. Por ello, en el presente estudio se examinaron comunidades aledañas a la Reserva de la Biósfera Los Petenes, ${ }^{2}$ que constituye la principal área donde se conserva esta actividad en Campeche.

\section{Metodología}

Área de estudio

Ubicación. La Reserva de la Biósfera Los Petenes (RBLP) es una franja costera con porciones terrestre y marina, localizada en la zona costera norte del estado de Campeche, en el sureste del Golfo de México. Colinda al norte con la Reserva

2 En adelante RBLP. 
de la Biósfera Río Celestún (RBRC), al oeste con el Golfo de México, al este con los municipios de Tenabo, Hecelchakán y Calkiní, y al sur con el municipio de Campeche (véase Mapa 1). La RBLP ocupa una extensión de 282,000 hectáreas. Fue declarada área natural protegida del estado de Campeche en 1996, y después como reserva de la biósfera en 1999 (CONANP, 2006).

Clima. El clima predominante en la zona centro-sur es cálido subhúmedo con lluvias en verano. Su clasificación es de clima tropical con invierno seco (Aw). En el norte es semiseco y seco cálido. Existen dos temporadas climáticas: época de secas, que se extiende de noviembre a abril, y época de lluvias, que abarca de mayo a octubre. En la época seca la temperatura y precipitación promedio mensual es de $25.5^{\circ} \mathrm{C}$ y $23 \mathrm{~mm}$ respectivamente, y de $28.4^{\circ} \mathrm{C}$ y $139.9 \mathrm{~mm}$ en la época de lluvias (CONANP, 2006).

Suelo. La reserva se encuentra ubicada sobre una plataforma de roca caliza, en la cual se distinguen cuatro tipos de suelos: gleisol calcárico y arcílico (60.8\%), solonchak arcílico (32.6\%), leptosol lítico y réndzico (5.5\%) y arenosol éutrico $(0.9 \%)$ (CONABIO, 2000; Palma et al., 2012).

Vegetación terrestre. En las orillas bajas y fangosas de la zona costera de la reserva predominan las comunidades de manglar (ocupan el $42.2 \%$ de la superficie terrestre). El manglar es de dos tipos: a) de borde y b) de cuenca. El pastizal del tipo tular (13.3\%) predomina en la planicie costera inundable. Los Petenes (13.5\%) se caracterizan por sus islas de vegetación en forma circular con disponibilidad de agua dulce todo el año proveniente de corrientes subterráneas. Dichas islas están conformadas por vegetación de selvas o una combinación de selva y manglar. En los suelos someros y pedregosos predomina la asociación de selva baja caducifolia y subcaducifolia (19.6\%). Un área importante de la superficie terrestre de la reserva está ocupada por blanquizales (10.5\%) (CONABIO, 2000).

La RBLP estuvo habitada desde tiempos prehispánicos por grupos mayas que dejaron vestigios arqueológicos de su presencia. Actualmente tiene mínima presencia humana. No obstante, colinda con 17 comunidades rurales (Mapa 1). La población asentada en las comunidades aledañas a la reserva es de 33256 habitantes y se concentra hacia el norte de ésta (INEGI, 2010).

Dadas las condiciones limitantes de los suelos para el desarrollo de la agricultura comercial, las principales actividades a las que se dedican en dichas comunidades son la agricultura tradicional de roza, tumba y quema, ${ }^{3}$ las artesanías de palma (especialmente sombreros), la elaboración de carbón vegetal, la apicultura, el cultivo de hortalizas en pequeña escala y la pesca (CONANP, 2006). De acuerdo con el Consejo Nacional de Evaluación de la Política de Desarrollo Social (CONEVAL), el $64 \%$ de la población es pobre en el municipio de Tenabo, $60 \%$ en Calkiní y 56\% en Hecelchakán. En el municipio de Campeche, donde se localiza la capital del estado, la pobreza alcanza al 35\% de la población (CONEVAL, 2010).

\footnotetext{
${ }^{3}$ En la agricultura tradicional o de milpa, en el sistema de roza, tumba y quema, que se practica en Los Petenes, Campeche, se asocian normalmente los cultivos de maíz, frijol y calabaza.
} 


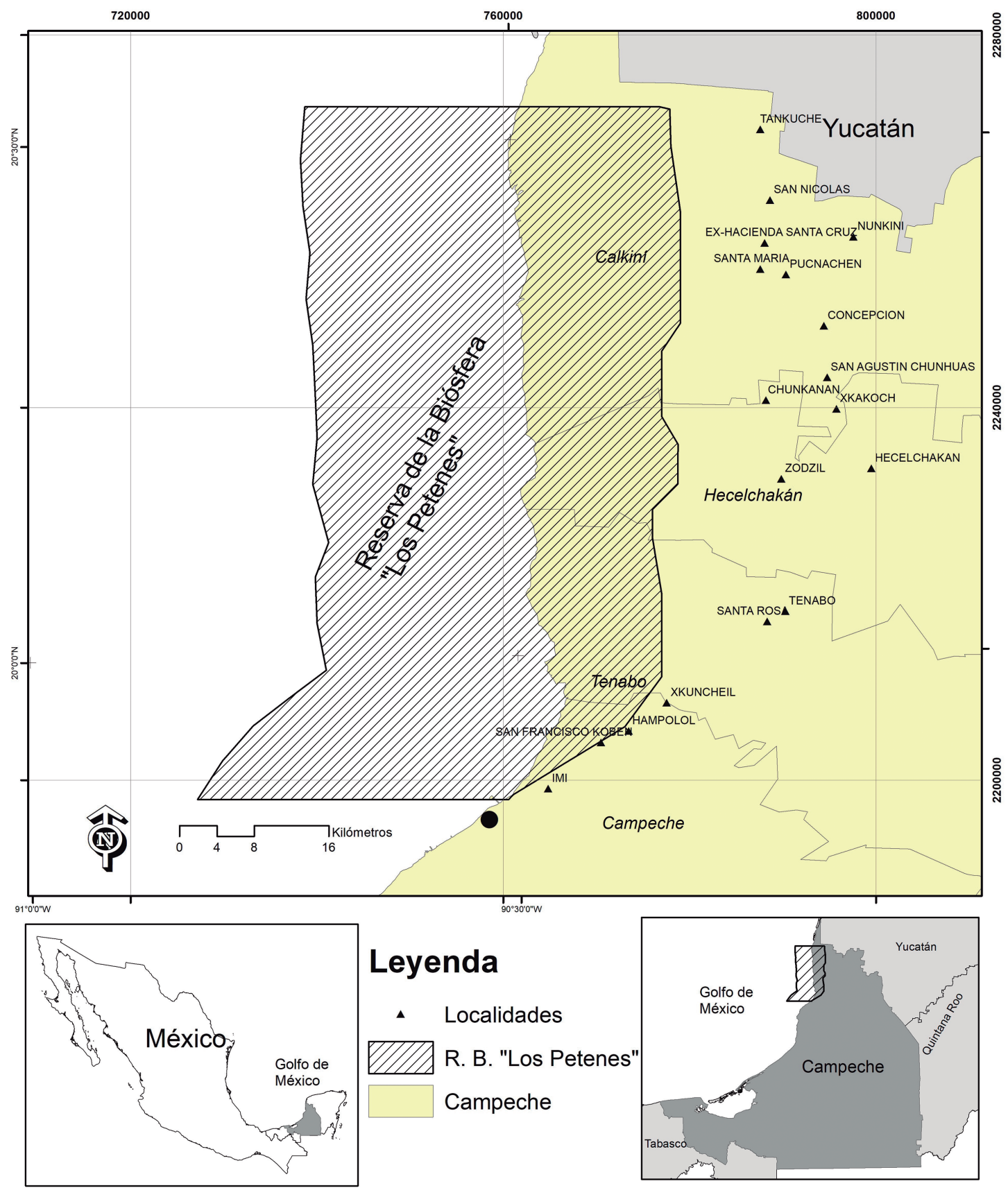

Mapa 1. Ubicación geográfica del área de estudio.

Elaborado por Rodimiro Reyes

(Sistema de Información Geográfica de El Colegio de la Frontera Sur). 


\section{Materiales y métodos}

La documentación de la meliponicultura en las comunidades aledañas a la RBLP se originó del trabajo que desde 2007 desarrolla el grupo académico Estudios Socioambientales y Gestión Territorial del Colegio de la Frontera Sur (ECOSUR). Con este antecedente se visitaron comunidades y se aplicó entrevistas preliminares a meliponicultores. Con base en tal información, se aplicó una encuesta semiestructurada y entrevistas a profundidad con informantes clave (Robles, 2011). Además, se aplicó la técnica de observación participante (Kawulich, 2005). El estudio se realizó en 17 comunidades aledañas a la RBLP, de las cuales solo en seis se conserva la meliponicultura: Tankuché, Pucnachén, Chunkanán, Concepción, Santa Cruz Exhacienda y Santa María (Mapa 1). En estas comunidades se censaron 30 familias campesinas mayas que crían la abeja Melipona beecheii. Una de estas familias, ${ }^{4}$ ubicada en Pucnachén, cuenta además con dos colonias de Nannotrigona perilampoides y tres de Frieseomelitta nigra, pero por ahora sólo las tienen como colección en su meliponario.

La encuesta aplicada constó de dos secciones: socioeconómica y productiva. La sección socioeconómica recopiló información sobre a) tamaño y composición de las familias, b) edad y escolaridad, c) organización social y productiva, d) comercialización de miel, e) actividades económicas y f) apoyos gubernamentales. La sección productiva recopiló información sobre a) número de colonias y producción de miel, b) el cuidado y manejo del meliponario, c) los usos y el consumo de miel, d) los aspectos culturales y la experiencia asociados a la cría de meliponas. Se indagó sobre las familias que habían perdido o abandonado las abejas ko'olel kaab y se procedió a ubicarlas y entrevistarlas. Se plantearon preguntas como ¿a quién pertenecían las colonias?, ¿cuántas colonias poseían?, ¿en qué año se perdieron las colonias y por qué? y si les gustaría recuperar la actividad.

Se realizó una entrevista a profundidad en cada comunidad con el meliponicultor de mayor experiencia y/o reconocimiento comunitario. También se les practicó una encuesta. Las temáticas abordadas fueron el manejo tradicional de las abejas, la organización social, los apoyos del gobierno y los cambios ocurridos en la meliponicultura. La encuesta y las entrevistas se realizaron entre marzo y noviembre de 2015. Además, se usó la técnica de observación participante para conocer en detalle las actividades de la cosecha de miel, la división y transferencia de cámaras de cría de las abejas, los usos de la miel y la cera y el control de plagas. Para ello se seleccionaron dos familias, una de ellas en la comunidad de Pucnachén y la otra en Tankuché.

\footnotetext{
${ }^{4}$ El jefe de familia es Enrique Uc Naal.
} 


\section{Resultados y discusión}

La meliponicultura en la estrategia campesina

En la Reserva de Los Petenes actualmente sólo 30 familias campesinas se dedican a la cría de abeja ko óolel kaab, de las cuales 13 se ubican en Tankuché, siete en Pucnachén, cuatro en Chunkanán, tres en Concepción, dos en Ex Hacienda Santa Cruz y una en Santa María (ver Mapa 1). De acuerdo con los recorridos de campo estimamos que en el estado de Campeche existen actualmente alrededor de cien meliponicultores, localizados en los municipios de Calkiní, Hecelchakán, Tenabo, Holpechén, Campeche y Champotón. En el estado de Yucatán, se estimó en 2001 la existencia de 500 meliponicultores que poseían en promedio diez colonias cada uno (Quezada, May y González, 2001: 163). En el estado de Quintana Roo, en 2004 se reportó la presencia de 120 meliponicultores. Según los reportes de Villanueva et al. (2005: 36), entre 1981 y 2004 descendió 93\% el número de colonias de abejas. Como hemos podido ver, dicha actividad es vulnerable por la escasa población de productores que la practican en la península de Yucatán, en especial en el estado de Campeche.

Referente a las familias campesinas dedicadas a la meliponicultura, 20 de ellas (67\%) tienen como actividad principal la agricultura tradicional de roza-tumbaquema; cuatro, la artesanía con palma de jipi; ${ }^{5}$ tres son apicultores de la especie Apis mellifera; una es ama de casa; otro se dedica a la pesca, y la tercera, a la meliponicultura. ${ }^{6}$ Respecto a las actividades secundarias más importantes, cinco de las familias se dedican a la artesanía, cinco a la ganadería bovina, cinco a los huertos y solares y tres a la meliponicultura.

Lo anterior es un indicador de que las familias campesinas se dedican a múltiples actividades agrícolas y no agrícolas que desarrollan a lo largo del año, ya sea de manera simultánea o estacional. Algunos estudiosos han denominado esta condición “estrategia de pluriactividad” (Rello, 2001: 60-66), término que se sustenta en el uso múltiple de los recursos (García, Toledo y Martínez, 2008; Toledo et al., 2008). El objetivo principal de esta estrategia campesina es garantizar el autoabasto familiar a través de la producción de alimentos provenientes de la milpa y, en segundo lugar, producir excedentes para el mercado (Terán y Rasmussen, 1994). En este contexto, la meliponicultura en la RBLP es primordialmente una actividad que complementa el ingreso de las familias campesinas para la compra de bienes y servicios que no produce. Generalmente, las colmenas de ko'olel kaab no se venden, sino que han sido dejadas en herencia o regaladas

\footnotetext{
${ }^{5}$ En los Petenes, la planta de jipi o jipijapa (Carludovica palmata) se usa principalmente para elaboración de sombreros tipo Panamá.

${ }^{6}$ Esta meliponicultora es la señora Leydi Chan de la comunidad de Tankuché. En 2015 tuvo 40 jobones y vendió 25 litros de miel (aproximadamente $31.25 \mathrm{~kg}$ ). Cada kilogramo fue vendido a 800 pesos. Ella es madre soltera con dos hijos, un varón de 6 años y una niña de 15. Para complementar sus ingresos se dedica a la repostería y la cría de animales de solar.
} 
por los padres o abuelos, quienes las han mantenido por varias generaciones y las consideran patrimonio familiar. Sin embargo, eventualmente los productores mayas venden colmenas para solventar gastos imprevistos relacionados con la salud o para saldar deudas en efectivo. Ello funciona como una caja de ahorro. Este comportamiento es similar al de los productores que practican la apicultura convencional con la especie A. mellifera (Güemes, Villanueva y Eaton, 2003: 157).

Descripción sociodemográfica de los meliponicultores

Las familias que crían la abeja ko'olel kaab son de origen maya yucateco. Siete hablan exclusivamente el idioma maya y 23 son bilingües: hablan maya y español. Diez viven en familias tipo nuclear y 20 son del tipo extenso. Las familias nucleares están conformadas por parejas jóvenes y ancianos solos. Los grupos extensos, formados por dos o más grupos nucleares, ocupan viviendas diferentes en un mismo solar y mantienen fuertes vínculos de cooperación productiva, intercambio de alimentos y cuidado mutuo. Algunos autores han denominado esta forma de conformación familiar como "grupo doméstico" (Pat et al., 2010: 49).

En las 24 familias que poseen la abeja ko'olel kaab, son los hombres quienes se dedican a la meliponicultura $(80 \%)$ y solo en seis familias las mujeres realizan esta labor (20\%). La edad promedio es de 63 y 62 años, respectivamente (Figura 1). Asimismo, el promedio de años de experiencia en el manejo de dichas abejas es de 30 y la escolaridad media de 4.1 años. En el estado de Yucatán el porcentaje de mujeres dedicadas a la meliponicultura es aproximadamente del 22\% (González, Quezada y Medina, 2006: 234), cifra similar a la encontrada en Los Petenes. Sin embargo, en Los Petenes la edad media por productor es 20 años mayor que en Yucatán. Respecto a la edad de los hombres, es ocho años menor en Yucatán que en las comunidades estudiadas. Lo anterior indica que la meliponicultura es una actividad dominada por hombres con bajo nivel de escolaridad y de poco interés para los jóvenes.

\section{Organización social}

La organización social de los grupos familiares y comunidades es importante dentro de la estructura social y económica para aprovechar las ventajas de mercado de los productos agropecuarios, en este caso, de la miel, el polen, el cerumen y los propóleos de las abejas sin aguijón. En zona de Los Petenes la organización es incipiente; en las comunidades aledañas solamente se detectó que en Pucnachén existen dos organizaciones relacionadas con la meliponicultura: la Cooperativa Pucnachén y el gremio de la Iglesia. La primera es una cooperativa legalmente constituida en 2011, que tiene como objetivo la producción y comercialización de fibras vegetales. Este grupo está formado por cinco socios que poseen un 


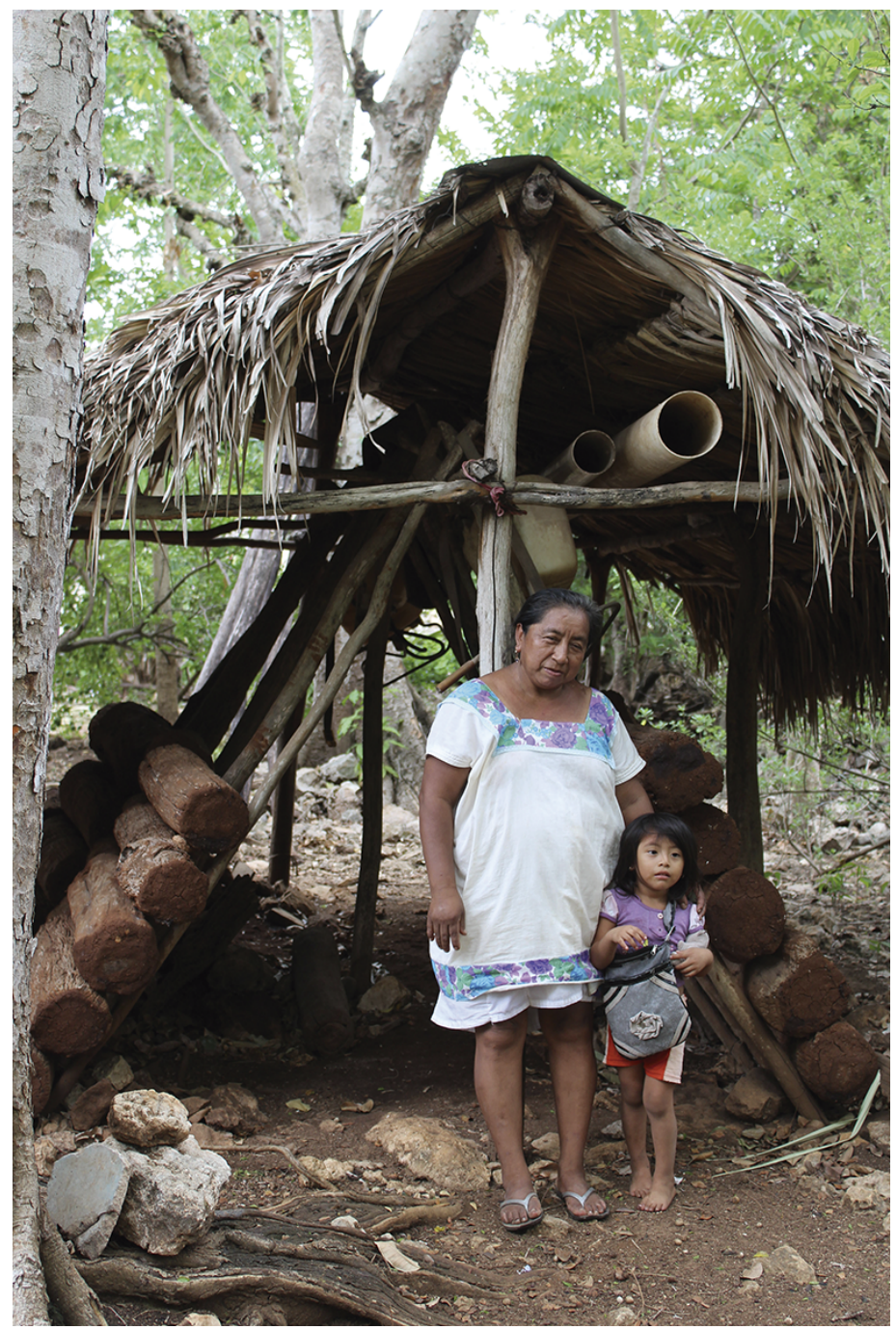

Figura 1. Meliponario y meliponicultora con su nieta en Pucnachén, Campeche. Fotografía de Lucio Alberto Pat-Fernández.

meliponario de 16 jobones, ${ }^{7}$ con los que pretenden agregar valor a través de la diversificación productiva. La segunda es un grupo informal fundado en 1965 y está integrada por 18 socios, de los cuales solo cinco se encuentran activos. El

${ }^{7}$ El jobón es un tronco hueco donde se cría una colonia de abejas ko'olel kaab. Los extremos del tronco se tapan con discos de madera y en el centro se ubica un agujero de aproximadamente dos centímetros que utilizan las abejas como entrada o salida. 
grupo posee un meliponario con 34 jobones y tiene como propósito recaudar fondos para la iglesia mediante la venta de miel. Los integrantes del primer grupo no le tienen confianza a su presidente en turno. En cuanto al segundo grupo, sólo cuatro personas participan en la producción y en la comercialización. A los demás miembros no les interesa colaborar en la meliponicultura y sólo quieren manejar el dinero de la venta de la miel, lo cual representa una limitante en el desarrollo de la organización.

En Tankuché, los meliponicultores tienen acceso a los apoyos y subsidios mediante una solicitud común que gestiona un líder ante las dependencias gubernamentales del sector primario. Esta forma de interacción entre los productores y las dependencias gubernamentales propicia a) la permanencia de relaciones clientelares y de corrupción entre los participantes y b) la formación de organizaciones con el objetivo de obtener apoyos y subsidios de gobierno (Rosales y Rubio, 2010: 176-178).

La experiencia ha demostrado que la organización social es un medio pertinente para aumentar la producción, para mejorar la calidad y el ingreso de las familias que se dedican a la meliponicultura. Por ejemplo, en Cuetzalan, Puebla, el grupo de productores de miel de la abeja Pitsilnejmej (Scaptotrigona mexicana) ha demostrado cómo la organización de productores puede fortalecer la meliponicultura. El grupo Pitsilnejmej forma parte de la Unión de Cooperativas Tosepan (UCT) y fue fundado en 1998 por 140 socios de origen náhuatl pertenecientes a 18 comunidades del municipio de Cuetzalan (Albores et al., 2011). El trabajo organizado del grupo partió del conocimiento tradicional de la cría y el manejo de las abejas; luego incursionó en la mejora de las prácticas de cosecha y postcosecha de la miel, y posteriormente se enfocó a la búsqueda de mercado y creación de valor agregado mediante la elaboración de productos cosméticos y suplementos alimentarios. Actualmente promueve el manejo tradicional para obtener la denominación de origen, el desarrollo de nuevos productos y la búsqueda de alianzas con otros actores para fortalecer la cadena de valor. Las transformaciones de la meliponicultura del grupo Pitsilnejmej son un modelo que puede ser de utilidad para la formación y consolidación de la organización social en Los Petenes.

Diversidad de especies de abejas sin aguijón

En la RBLP los apicultores mayas identifican nueve especies de abejas sin aguijón: k'antsak (Scaptotrigona pectoralis), sak xik (Frieseomelitta nigra), cho'o'ch (Partamona bilineata), limón kaab (Lestrimelitta niitkkib), múul kaab (Trigona fulviventris), us kaab (Plebeia moureatana), bo'ol (Nannotrigona perilampoides), taah kaab (Cephalotrigona zexmeniae) y ko'olel kaab o p'ol kaab (Melipona beecheii).

En colecta de campo de abejas sin aguijón en la RBLP hemos identificado hasta ahora ocho especies (todas las arriba mencionadas, excepto Plebeia moureatana). No obstante, en la península de Yucatán se ha reportado la presencia de 19 especies de abejas sin aguijón (Ayala, González y Engel, 2013: 139-144). A pesar de la 
diversidad de especies de abejas sin aguijón presentes en la reserva, los productores mayas únicamente crían la abeja Melipona beecheii. La preferencia por la abeja ko'olel kaab (Figura 2) puede deberse al mayor rendimiento de miel por colonia en comparación con las otras especies de abejas sin aguijón, como Frieseomelitta nigra, Cephalotrigona zexmeniae y Scaptotrigona pectoralis, y a las propiedades medicinales atribuidas a la miel de la melipona (Vit, Medina y Enríquez, 2004: 2), también al tamaño del nido, la docilidad de la abeja, el sabor y el color dorado de la miel (Quezada, May y González, 2001: 161). En Los Petenes, a la miel de ko'olel kaab se la considera una medicina, y se usa principalmente para tratar la gripa, la tos, las cataratas, las infecciones de los ojos, como la conjuntivitis, las quemaduras de la piel y el asma. También se emplea para estimular la producción de leche materna y como endulzante de la yuca (Manihot esculenta), el camote (Ipomoea batatas), la calabaza o nuuk k'úum (Cucurbita moschata) y el pan de buñuelos.

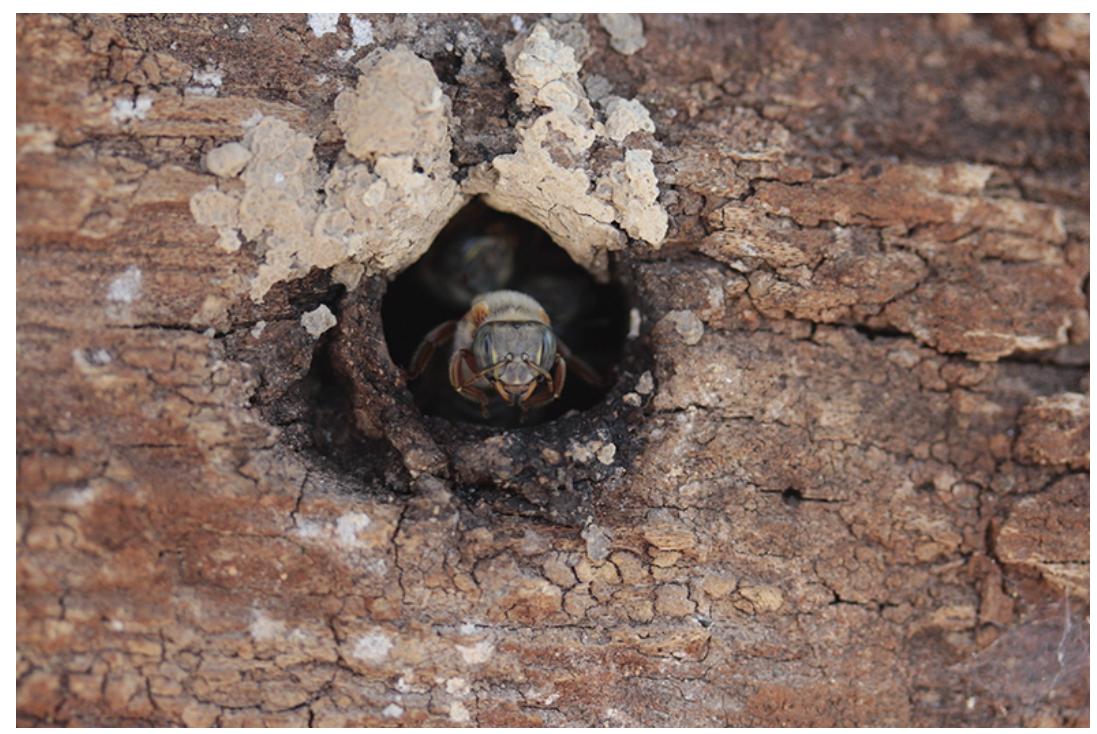

Figura 2. Abeja guardiana de ko’olel kaab en entrada de jobón. Fotografía de Lucio Alberto Pat Fernández.

\section{Producción y manejo tradicional}

\section{Producción}

En Los Petenes, a pesar de la diversidad de abejas sin aguijón, los productores mayas crían exclusivamente la abeja sin aguijón de la especie Melipona beecheiii. ${ }^{8}$

${ }^{8}$ Como se mencionó, sólo un meliponicultor tiene cinco colonias de otras especies de abejas sin aguijón, pero únicamente como colección. 
Las colonias de esta especie se crían en troncos huecos de aproximadamente $50 \mathrm{~cm}$ de largo, $30 \mathrm{~cm}$ de ancho y $5 \mathrm{~cm}$ de grosor, conocidos localmente como jobones. Los jobones más antiguos se elaboraban de cedro (Cedrela odorata), chicozapote (Manilkara zapota) y yaxnik (Vitex gaumeri), pero, dada su escasez en la región, ahora se emplea tzalam (Lysiloma bahamensis) y jabín (Pisidia piscipula). En la parte media del jobón se ubica un agujero de 1-2 cm que sirve como entrada a la colonia. Los extremos se tapan con discos de madera. Para sellar los discos se usa tierra arcillosa mezclada con hierbas para mayor consistencia. La cámara de cría se ubica en el punto medio del jobón y en los extremos las abejas elaboran potes de cerumen ${ }^{9}$ donde almacenan miel y polen. Los jobones se apilan en forma horizontal sobre una estructura piramidal en una casa rústica de techo de palma (Sabal mexicana) y soportes de madera. La casa de las abejas, conocida con el nombre de najil kaab, se ubica en todos los casos en la parte trasera de la vivienda principal, lo que permite una constante revisión.

En el área de estudio se ha propuesto a algunos productores el reemplazo de los jobones por cajas racionales, ${ }^{10}$ pero la propuesta no ha tenido aceptación, debido a que no se ha realizado una adecuada demostración de sus ventajas. En la localidad de Pucnachén se encontró que un meliponicultor tiene la mitad de las colonias de ko'olel kaab en jobones y la otra mitad en cajas racionales. La adopción de cajas racionales se debió a que este productor se asoció con un consultor para el establecimiento de un meliponario con fines comerciales y académicos.

Las cajas racionales tienen como propósito facilitar la cosecha, la limpieza de la miel, la división y la inspección de la colonia (Quezada, May y González, 2001: 165; Cortopassi et al., 2006: 4). Según la especie de abeja sin aguijón que manejan las familias, se dispone de dichas cajas con diferentes modelos y tamaños (Cortopassi et al., 2006: 4). Para el caso de Melipona beecheii, se sugiere el uso de cajas simples de $15 \mathrm{~cm}$ de alto, $15 \mathrm{~cm}$ de ancho y $45 \mathrm{~cm}$ de largo (Villanueva, 2015: 42). En todo caso, la dimensión de la caja depende del tamaño del nido (número de panales) que se va a transferir y de la capacidad de termorregulación de la colonia (Quezada y González, 1994: 167-169; Enríquez, Yurrita y Dardón, 2006: 25-26).

La cosecha de miel en Los Petenes se realiza en dos periodos: el primero entre los meses de abril y mayo, y el segundo entre octubre y noviembre. En el primer periodo se obtiene el 67\% de la producción total y en el segundo periodo el 33\% restante. Cabe destacar que la primera cosecha coincide con la época más seca y de mayor floración en la zona, y la segunda cosecha ocurre al término de la temporada de lluvias. Esta última cosecha se realizaba antes en el mes de octubre, con el propósito de tener miel para la elaboración de dulces que se ofrendaban el

\footnotetext{
${ }^{9}$ El cerumen es una mezcla de cera con resinas de árboles, las resinas se conocen también con el nombre de propóleo.

${ }^{10}$ Una caja racional es una caja de madera donde se transfiere desde un jobón una colonia de abeja ko'olel kaab.
} 
Día de Muertos. El día de cosecha se determina por la presencia de luna llena, ya que, de acuerdo al conocimiento ancestral, la miel se conservará por más tiempo y se tendrán suficientes crías maduras en los panales para hacer la transferencia y mayor probabilidad para establecer una nueva colonia.

El principal producto del meliponario es la miel, no obstante, también obtienen cerumen y polen. En las comunidades de estudio, de un total de 30 meliponicultores, 10 aprovechan el cerumen, siete el polen, cuatro la cera y el polen y nueve ninguno de los dos. El cerumen extraído durante la cosecha se usa para la elaboración de velas que se emplean en las ceremonias durante la celebración del Día de Muertos y en otras actividades religiosas de las comunidades. El polen se suele mezclar con la miel para obtener un jarabe medicinal.

Los productores tienen en promedio 15 jobones con rendimiento medio anual de $1.02 \mathrm{~kg} / \mathrm{jobón}$. Así, la producción total de miel de la abeja ko'olel kaab en la reserva se estimó en $463 \mathrm{~kg}$ en el año 2015. El rendimiento de miel de las abejas sin aguijón oscila sensiblemente de acuerdo a la especie de que se trate y el sitio donde se ubiquen los meliponarios. Por ejemplo, se reportó una producción cercana a seis litros de miel para Melipona subnitida en la región de Caatinga, Brasil (Cortopassi et al., 2006: 5). En México, para la especie de Melipona beecheii se reporta un rendimiento anual entre 2 y $2.5 \mathrm{~kg} /$ colonia (Villanueva, Roubik y Colli, 2005: 39; Alves, 2013: 543). No obstante, la productividad depende de varios factores como la abundancia de recursos florales, la competencia con otras especies de abejas y el manejo (Villanueva, Roubik y Colli, 2005: 37-40). Con el fin de aumentar el rendimiento, algunos conocedores del tema sugieren practicar la meliponicultura migratoria que busca la disponibilidad de floración en diferentes épocas del año (Alves, 2013: 542).

\section{Manejo tradicional}

El rescate de los conocimientos del manejo meliponario que realizan los productores mayas es la base más importante para el mejoramiento e innovación, con la finalidad de elevar la productividad e inocuidad del producto. Ellos tienen un calendario de actividades típico del meliponario que incluye básicamente el control de plagas, la cosecha y la división.

Control de plagas. La inspección y cuidado son actividades que se realizan todo el año. Consisten en prevenir daño de hormigas y moscas principalmente. El $47 \%$ de los meliponicultores señalan que la principal plaga es la hormiga arriera (Eciton burchelli parvispinum) conocida en maya con el nombre de xuulá, el $20 \%$ la mosca parasitaria nenem (Pseudohypocera kerteszi) y el 33\% no reportó problemas de plagas. El ataque de hormiga arriera ocurre generalmente durante la época de lluvias, que es de junio a septiembre. El control de plagas lo realizan los mayas con la aspersión de detergente disuelto en agua. El ataque de la mosca nenem ocurre durante la cosecha y las divisiones de los jobones. En la época de seca es cuando mejor se controla la plaga, pues hay menor incidencia de la mosca. 
También se usan hojas de tok'aban (Pluchea odorata), chakaj (Bursera simaruba) y guayaba (Psidium guajaba) como repelentes naturales. En el estado de Yucatán se reporta el uso del chakaj (Bursera simaruba), ruda (Ruta chalapensis) e ik-kabán (Croton humilis) (González, Quezada y Medina, 2006: 235); sin embargo, a esta última planta en Los Petenes se le considera peligrosa ya que su resina puede causar ceguera en animales y personas. Estas prácticas de control y la ausencia de plagas como la varroa (Varroa jacobsoni), que atacan a Apis mellifera y no a Melipona beecheii, han permitido la producción de miel de ko'olel kaab libre de uso de pesticidas.

Cosecha. En el proceso de la cosecha, el jobón se abre y se revisan las condiciones de llenado de los potes de miel y polen de la colmena. Si el jobón se encuentra con muchos potes bien llenos de miel, entonces la colonia se considera fuerte y se procede a su cosecha. Los potes de miel y polen se cosechan de forma separada, aunque algunos productores mezclan las dos sustancias intencionalmente para usarse como tónico contra la tos y gripa. Generalmente, no se cosechan todos los potes de miel y polen, sino que se dejan reservas para la época de lluvias, que es de escasa floración. Esta práctica permite eliminar la alimentación artificial de la ko'olel kaab.

Durante la cosecha el $63.05 \%$ de los productores realiza la ofrenda maya conocida como saká para agradecer a los dioses del monte por permitir la colecta de miel. El saká es una bebida hecha a base de maíz y endulzada con miel de ko'olel kaab recién cosechada. La miel de ko'olel kaab se utiliza también como ingrediente para la elaboración del ba'alché, una bebida maya que se emplea en la ceremonia de petición de lluvia ch'a'cháak y en la ceremonia de agradecimiento por la cosecha lograda jaanlil kool (Figura 3). El uso medicinal de la miel y las ceremonias asociadas a ella está desapareciendo gradualmente debido al sometimiento de los mayas a la cultura occidental (Ocampo, 2013: 238).

División. Se refiere a la transferencia de panales de cría de las colonias de abejas establecidas en jobones a un nuevo jobón para fundar una nueva colonia. La división es una práctica que realiza el $77 \%$ de los meliponicultores, pero solo el $20 \%$ de las veces resultan exitosas. Las fallas en la división se deben al ataque de la mosca nenem que oviposita en los panales de cría o potes de polen y posteriormente se alimentan de los mismos cuando se convierten en larvas.

Para establecer una nueva colonia se necesita al menos cinco panales, lo que se requiere disponer de al menos tres jobones. Para mejorar las oportunidades de éxito de la división, se deben usar panales maduros, es decir, en estadios de pupa o de adulto, y transferir suficientes abejas obreras para tener una colonia lo más fuerte posible. Para alimentar a la nueva colonia se introducen potes de miel y de polen que no estén rotos o expuestos, ya que el olor de éstos atrae a las hormigas y a la mosca nenem. También es recomendable realizar la división en la temporada seca, que coincide con la de menor incidencia de la mosca nenem y con la temporada de abundante floración, lo cual asegura la disponibilidad de alimento para la nueva colonia. 


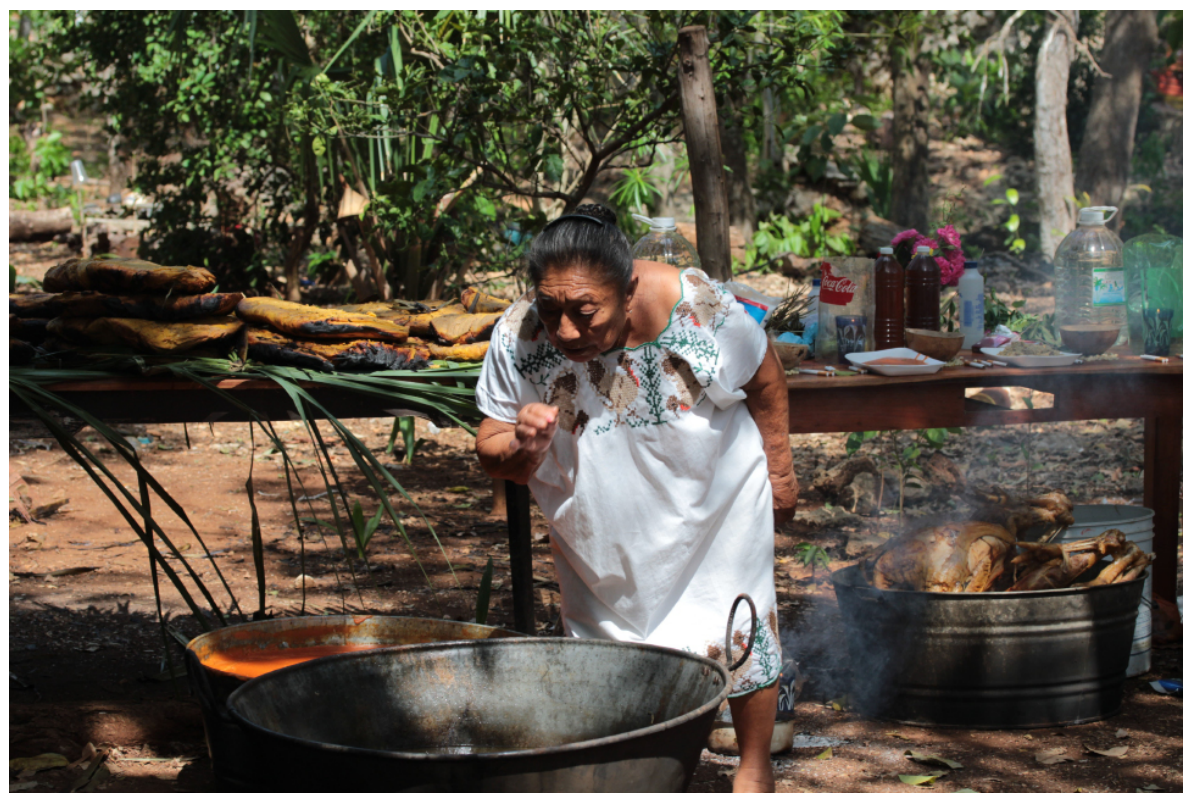

Figura 3. Ceremonia de jaanlil kool con ofrenda de saká y miel en la mesa. Fotografía de Lucio Alberto Pat-Fernández.

Durante el proceso de división y transferencia con el uso de cajas racionales, algunos investigadores sugieren el uso de recipientes con vinagre (ácido acético) al interior de éstas, el cual actúa como trampa para el nenem (González, 2008: 151-155). Existen reportes de que el uso del vinagre no aumenta la infestación de nenem en los nidos de las abejas (Olivera, Venturieri y Contrera, 2013: 203-208); sin embargo, el porcentaje de captura es muy bajo (Ruano, 2007: 3-7).

Para rescatar y fomentar la meliponicultura se ha propuesto a) sustituir el uso de jobones por cajas racionales para mejorar el manejo de alimentación y cosecha; b) controlar las plagas y parásitos que atacan colonias de abejas; c) impartir cursos prácticos de capacitación a productores, con énfasis en la reproducción de colonias y el manejo de éstas, y d) buscar usos alternativos de colonias de abejas como, por ejemplo, la polinización de cultivos de chile habanero y tomate (González, Quezada y Medina, 2006: 236).

\section{Características de la miel de ko'olel kaab}

En general, la miel de ko'olel kaab y otras especies de abejas sin aguijón es más ácida y húmeda que la de Apis mellifera (Vit, Medina y Enríquez, 2004: 3-4). La humedad elevada $(>20 \%)$ favorece una rápida fermentación de la miel y, por lo tanto, adquiere un sabor agrio. En condiciones de almacenamiento a temperatura 
ambiente, la miel de Melipona beecheii procedente de Los Petenes demoró 90 días antes de fermentar. Para reducir la humedad y prolongar el tiempo de inicio de fermentación de la miel se puede optar por deshumidificarla o mantenerla en refrigeración. La deshumidificación es una técnica de bajo costo que prolonga la vida de anaquel de la miel sin alterar su calidad fisicoquímica y organoléptica (Carvalho et al., 2009). La mayor acidez y humedad característica de la miel de abeja sin aguijón no deben asociarse a una calidad inferior: simplemente es un tipo de miel específico para el cual no existen normas de calidad nacionales ni internacionales (Vit, 2008: 22; Almeida et al., 2013: 1699).

Una manera de revalorar y diferenciar las mieles de las abejas sin aguijón es mediante el conocimiento de sus propiedades fisicoquímicas, su bioactividad, su origen floral y su caracterización sensorial (Vit, 2008: 22). Sin embargo, la mayor parte de los estudios disponibles en esta materia se han realizado en diferentes regiones de Brasil y en un pequeño grupo de especies (Alves et al., 2005: 644-650; Souza et al., 2006; Carvalho et al., 2009; Lage et al., 2012: 605-608). En México se encuentran escasos reportes acerca de las propiedades fisicoquímicas y organolépticas de la miel de la abeja Melipona beecheii, no obstante que este país se considera como centro del surgimiento de la meliponicultura en América.

\section{Venta y consumo}

Como es sabido, la oferta y demanda son el mecanismo que regula los precios de compra y venta de los bienes. En el caso de la miel de Melipona beecheii, la escasez y atributos medicinales desempeñan un papel determinante en la fijación de su precio local y regional. Los meliponicultores de la reserva venden en promedio el $88.5 \%(13.65 \mathrm{~kg})$ de la miel cosechada, y el $11.5 \%(1.77 \mathrm{~kg})$ restante queda para consumo familiar. La miel se vende a compradores locales e intermediarios de la región. El precio de venta en 2015 osciló entre \$50/kg y \$800/kg (US\$2.9046.5). ${ }^{11}$ Setenta por ciento de los productores vendió a $\$ 400 / \mathrm{kg}$ (US\$23.2). A este precio, cada familia tuvo un ingreso medio de $\$ 6,000$ que representó aproximadamente el $60 \%$ del ingreso percibido por PROSPERA, el principal programa social en México.

La diferencia de ingreso que la familia recibe por la venta de miel depende de los tipos de intermediarios que controlan la región. Los intermediarios locales o regionales generalmente venden a empresas acopiadoras establecidas en la ciudad de Mérida, Yucatán. El precio de venta de la miel de los intermediarios a las empresas acopiadoras varía entre $\$ 1,000 / \mathrm{kg}$ y $\$ 1,200 / \mathrm{kg}$ (58.1-69.7 USD, respectivamente). En 2015, el precio fue 25 y 30 veces mayor que el precio del kilogramo de la miel convencional de la especie Apis mellifera.

\footnotetext{
${ }^{11}$ De acuerdo con el Informe Anual 2016 del Banco de México, el tipo de cambio de pesos por dólar fue de \$17.2 en el 2015.
} 
En Brasil el precio de la miel de abejas sin aguijón depende de la especie y la zona productora; por ejemplo, el precio de la miel de Melipona compressipes osciló en 10-18 USD por kilogramo en Maranhão en 2005, y el precio de la miel de Tetragonisca angustula entre 21.00-32.00 USD por kilogramo en Bahía y Paraná (Alves, 2013: 549). En Costa Rica, el precio de la miel de abejas sin aguijón oscila entre 20-50 USD por litro y, en envases de $10 \mathrm{ml}$, entre 2 y 4 USD (Aguilar, Herrera y Zamora, 2013: 119). En Australia el precio del kilo a menudeo de la miel de abejas nativas sin aguijón es de hasta 24.6 dólares australianos (AUD), superior al precio de la miel de Apis Mellifera (Halcroft, Spooner y Dollin, 2013: 55).

En la reserva de Los Petenes, la miel de las abejas sin agujón tiene un precio superior al de la miel de Apis mellifera debido a que la población que la demanda la prefiere por sus propiedades nutritivas y medicinales, por su rareza y por ser un producto orgánico (Vit, Medina y Enríquez, 2004; Halcroft, Spooner y Dollin, 2013: 55). En la reserva, la miel para consumo familiar se usa principalmente con fines medicinales (76\%) y en menor proporción para endulzar alimentos (24\%). El consumo de miel de Melipona beecheii en la región es muy bajo, porque los precios son muy elevados para la mayor parte de las familias mayas.

Las familias que no crían Melipona beecheii con frecuencia colectan miel de abejas sin aguijón para consumo medicinal de las especies Frieseomelitta nigra y Cephalotrigona zexmeniae. La primera es una especie abundante que anida en la selva baja en los alrededores de las comunidades y en las paredes de las casas. La segunda es una especie menos común que se encuentra con mayor frecuencia en árboles maduros (yaxnik). Durante la extracción de la miel de estas especies generalmente se destruyen las colonias de las abejas.

\section{Evolución y perspectivas de la meliponicultura en Los Petenes}

El censo realizado en las comunidades aledañas a la RBLP indica que en 2015 existían 30 meliponicultores que poseían un total de 449 colonias y un promedio de 15 colonias por productor (Gráfica 1). De los 30 productores, seis se incorporaron en el 2011 como resultado de un programa de fomento de la meliponicultura apoyado por la Comisión Nacional de Áreas Naturales Protegidas.

La meliponicultura en la Reserva tuvo importantes cambios en el pasado. La memoria de las familias permitió remontarnos hasta 1940. Entre 1940 y 2014, 47 meliponicultores abandonaron la actividad. Estos productores poseían un total de 1320 colonias y un promedio de 28 colonias per-cápita (Gráfica 2). De esta forma, en dicho periodo, el número de productores y de colonias se redujo en $163 \%$ y $295 \%$ respectivamente. Asimismo, el $31.9 \%$ de las familias entrevistadas mencionó que perdieron sus colonias debido al abandono, $21.3 \%$ a la venta, $12.7 \%$ al deficiente manejo, $6.4 \%$ a la sequía y las inundaciones, $6.4 \%$ porque las regalaron, $6.4 \%$ a causa del ataque de hormigas y $14.9 \%$ no pudo recordar ninguna causa. 


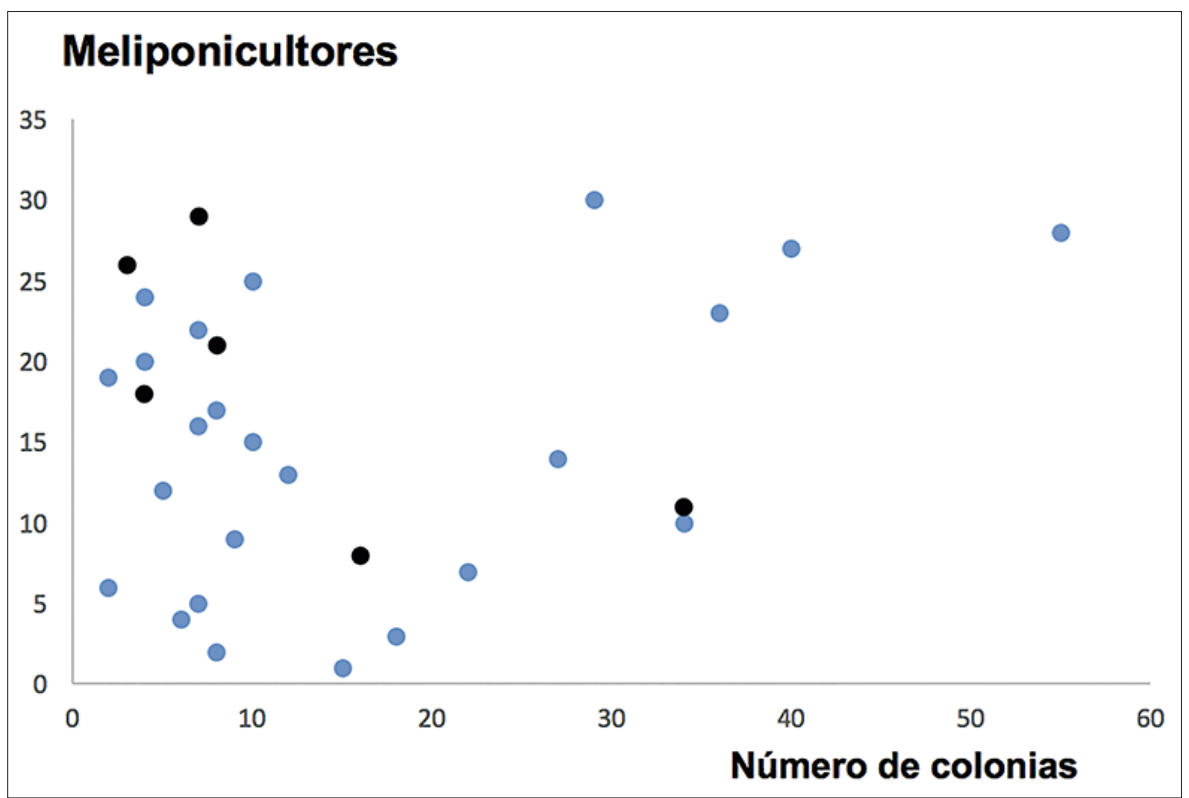

Gráfica 1. Número de colonias de Melipona beecheii en la RBLP, 2015.

Fuente: Trabajo de campo 2015.

Nota: Los puntos remarcados en negro representan a meliponicultores incorporados en 2011.

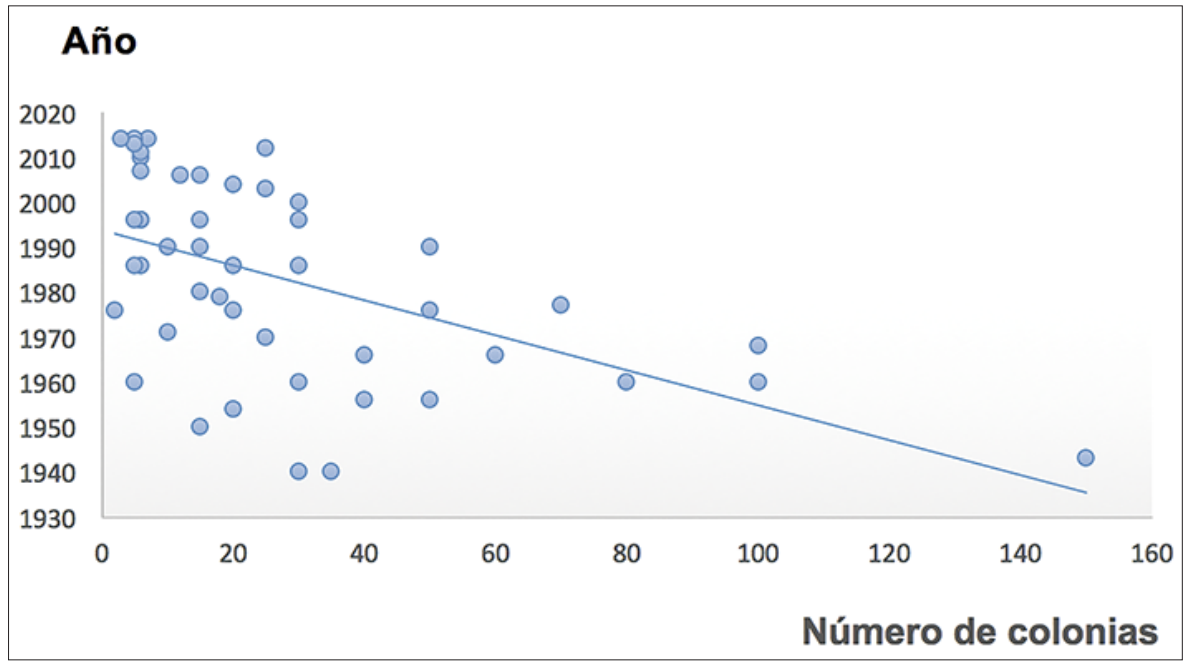

Gráfica 2. Número de colonias de M. beecheii en la RBLP, 1940-2014.

Fuente: Trabajo de campo 2015. 
Las condiciones desfavorables reflejan las problemáticas que limitan la producción y el manejo de la abeja sin aguijón. Un factor que inició el decaimiento de la meliponicultura fue la introducción de la abeja europea Apis mellifera, que desplazó la cría de la Melipona beecheii. Aunque la Apis mellifera fue introducida por colonizadores españoles al continente americano en el siglo xvl, no fue sino hasta principios del siglo xx que se empezó a criar esta especie en la península de Yucatán. La criaban los hacendados para la producción comercial de miel. Sin embargo, entre 1965 y 1975, aproximadamente, la adoptaron ampliamente los productores mayas (Rosales y Rubio, 2010: 168). La adopción y expansión de la apicultura con Apis mellifera se debe a que es compatible con el ciclo de la milpa. Además, el mayor rendimiento de miel por colonia, en comparación con la abeja ko'olel kaab, permite obtener producción excedente para su venta (Terán y Rasmussen, 1994: 270-272; Rosales y Rubio, 2010: 169).

Durante el periodo referido y hasta mediados de la década de 1990, la miel de ambas especies se consideraba un producto idéntico en cualidades y precio. Por tal razón, la mayoría de los meliponicultores de la RBLP mezclaba la miel de Apis mellifera con la de Melipona beecheii para su venta.

Antes la miel de Melipona se pagaba igual que la miel de la abeja europea. Por eso mezclábamos. Ahora ya no, un litro de Melipona llega a valer hasta 10 veces más que la de la abeja extranjera (meliponicultor de Tankuché, Campeche, 2015).

Con el transcurso del tiempo, la meliponicultura perdió importancia en la reserva y muchos meliponarios fueron abandonados (Figura 4).

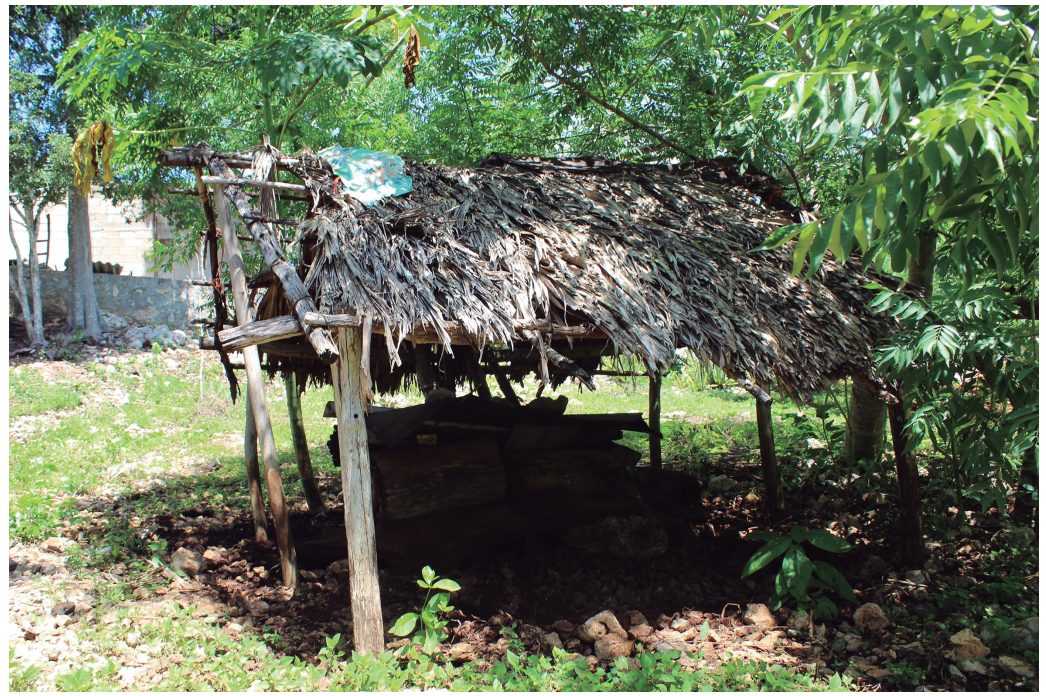

Figura 4. Meliponario abandonado en Concepción, Campeche. Fotografía de Lucio Alberto Pat Fernández. 
Por otra parte, las colonias de ko'olel kaab no suelen venderse (o comprarse) debido a que las familias mayas las consideran un legado ancestral. No obstante, para atender emergencias de salud, acostumbran vender colonias. Por ejemplo,

Estas abejas me han sacado de apuros, este año (2015) necesité dinero para ir con el doctor a Mérida y me vi en la necesidad de vender tres jobones aunque mi esposa no estuvo de acuerdo (meliponicultor de Tankuché, Campeche, 2015).

En la reserva se documentó que, cuando algún meliponicultor no puede atender su meliponario o fallece, las colonias de abejas se heredan a los hijos, se venden o, en última instancia, se regalan a vecinos o amigos. La venta de colonias de abejas en la reserva está favoreciendo la concentración de éstas en dos meliponicultores que se iniciaron en 2011, uno ellos localizado en Pucnachén y el otro en Tankuché.

La decadencia de la meliponicultura en la reserva también ocurre por la pérdida gradual de conocimiento del manejo tradicional. Al respecto, es importante señalar que $50 \%$ de los meliponicultores transmiten conocimiento sobre el manejo de la abeja a sus hijos y $12 \%$ a otros familiares. Sin embargo, se observa que un número significativo de ellos (32\%) lo transmite y solo una fracción (6\%) lo ha adquirido en cursos de capacitación formal. Lo anterior evidencia la importancia de conservar los saberes locales y el adiestramiento como un medio para fomentar la meliponicultura en la reserva. La capacitación y el intercambio de experiencias puede implementarse con el enfoque llamado de "productor a productor" (Ramos et al., 2016: 293). Este tipo de interacción intenta suplir la ausencia de la enseñanza formal, rescatar el conocimiento tradicional y afianzar la colaboración entre los meliponicultores. La pérdida de conocimiento tradicional puede asociarse a la falta de interés de los jóvenes (González y Quezada, 2011: 384), quienes emigran a centros urbanos para estudiar o trabajar.

La sequía y las inundaciones causan pérdidas en las colonias de abejas. Aunque suelen ser eventos ocasionales del clima, pueden provocar grandes bajas. De acuerdo con los datos de las dos estaciones meteorológicas más cercanas a la Reserva, la precipitación pluvial promedio del periodo de 1980 a 2011 fue de 1 $158 \mathrm{~mm}$ anuales (CNA, 2014). El año más seco fue 1986; se registroaron apenas $689 \mathrm{~mm}$ de precipitación pluvial, mientras que en 1995 se tuvo el registro más lluvioso con $1433 \mathrm{~mm}$. El primero afectó la producción por la sequía y poca floración de la vegetación de la región; el segundo favoreció la producción de miel. Los huracanes son otro evento climatológico que ha dañado la meliponicultura (Villanueva, Roubik y Colli, 2005: 40).

En septiembre de 1988 cuando pego el huracán Gilberto tenía 100 jobones y solo me quedaron 15, los demás se los llevó la corriente o se ahogaron las abejitas... desde ese entonces no tengo más colonias de ko'olel kaab (meliponicultor, Chunkanán, Campeche 2016). 
Otro elemento que explica la pérdida de la meliponicultura son las plagas, como los ataques, aunque esporádicos, de la hormiga xuulá. Las hormigas pueden acabar con un meliponario completo si no se detectan y controlan a tiempo, como comentan los meliponicultores:

Durante muchos años tuve cuatro jobones de ko 'olel kaab y a finales del año pasado (2015) los perdí por culpa del xuulá que entró en la noche y no me di cuenta hasta el otro día (meliponicultor de Tankuché, Campeche, 2015).

Finalmente, la deforestación de la selva para la elaboración de carbón vegetal y la extracción de leña está reduciendo el hábitat de las abejas sin aguijón, como Frieseomelitta nigra, Cephalotrigona zexmeniae y Scaptotrigona pectoralis en el área aledaña a la RBLP (Pat et al., 2016). Esta condición es particularmente grave en las comunidades de Chunhuás, Chunkanán y Xkacoch (Pat et al., 2008: 143-145). En Chunhuás se observó que para la elaboración de carbón se queman ramas y troncos con colonias de abejas en su interior, aunque cuando se detectan colonias de abejas grandes se extrae la miel antes del proceso de carbonización. Se ha documentado también que la deforestación y fragmentación de la selva afecta la diversidad, la dominancia y dispersión de las abejas sin aguijón (Meléndez, Meneses y Kevan, 2013). En Quintana Roo, Cairns et al. (2005) encontraron que los ecosistemas con mayor perturbación antropogénica poseen menor riqueza de abejas sin aguijón en comparación con los ecosistemas mejor conservados, aunque en ambos ambientes tiene dominancia Apis mellifera. Asimismo, la tala selectiva de árboles grandes reduce el hábitat de especies como Melipona beecheii, Mellippona yucatanica, Scaptotrigona pectoralis y Cephalotrigona zexmeniae, y abre nuevos espacios para otras especies, como Trigona fulviventris (Cairns et al., 2005: 688-689). Las actividades de elaboración de carbón vegetal y la extracción de leña forman parte de la estrategia de diversificación de las familias mayas. Por eso dichas actividades tienen pocas probabilidades de desaparecer. No obstante, es factible la conservación y el aprovechamiento de las especies Frieseomelitta nigra y Cephalotrigona zexmeniae mediante su cría, como ocurre en Costa Rica (Aguilar, Herrera y Zamora, 2013: 115-118).

Pese a las condiciones desfavorables indicadas, existen otras que fomentan e incentivan la meliponicultura de forma sostenible, como a) las diferentes especies vegetales locales que ofrecen buenas floraciones debido a las condiciones climáticas favorables que se presentan en la reserva, b) la meliponicultura se practica en un área natural protegida en la RBLP que brinda una oportunidad idónea, debido a que el manejo y uso de los recursos naturales están sujetos a las leyes que los protegen de la depredación antropogénica, c) en el área de producción existe e impera la cultura maya, que tiene conocimiento y experiencia en el manejo de las abejas nativas, que proveen alimento a la familia con diferentes usos, medicinal, religioso y fuente energética para endulzar comidas, y d) la cría de abejas nativas, en especial, ko'olel kaab (y sus productos derivados) posee diferentes valores eco- 
lógicos, culturales y sociales a los de la miel de Apis mellifera y no se han fomentado mercados alternativos para obtener mejores condiciones de comercialización.

\section{Conclusiones}

La meliponicultura constituye una actividad económica poco estudiada en Campeche. Está presente en un grupo reducido de comunidades, 35\% del total de 17 aledañas a la Reserva de la Biósfera de Los Petenes. En los procesos socioambientales de las familias campesinas mayas dicha actividad está manejada principalmente por hombres, la participación de las mujeres representa sólo un $20 \%$. Sin embargo, forma parte de la estrategia productiva para enfrentar las condiciones adversas de reproducción familiar. La organización social para la producción y el manejo de la meliponicultura en Los Petenes se considera incipiente por el disperso y reducido número de productores. Además, la escasa presencia de programas de apoyo limita la actividad ancestral en la reserva.

Los meliponicultores de Los Petenes, a pesar de que existe gran diversidad de especies de abejas nativas, aprovechan y manejan únicamente la especie Mellipona beecheii, cuyo rendimiento es aproximadamente un litro por colonia, que está por debajo del promedio en México. Generalmente, los intermediarios adquieren la producción de miel de las familias mayas a un precio bajo y la revenden a precios muy altos, por lo que se considera importante buscar alternativas de mercado, como la venta directa a los minoristas y al consumidor para beneficio de las familias mayas. Se encontró que el manejo y la reproducción de la abeja nativa de Los Petenes son similares a los de otras áreas de la península de Yucatán, por tener condiciones naturales y culturales análogas, aspecto que fue previsto en el presente estudio.

La meliponicultura en la reserva - no obstante las condiciones adversas que limitan la producción, como las sequías, los ciclones, la deforestación y los bajos precios de los intermediarios - presenta características particulares que favorecen el desarrollo de la actividad, que se encuentra en el contexto de un área natural protegida, la Reserva de la Biósfera Los Petenes, donde predomina la riqueza vegetal. Además, es amigable y sostenible. Por otra parte, el manejo y la producción todavía la realizan familias con tradición de la cultura maya que tienen conocimientos y experiencia para fomentar y fortalecer la meliponicultura en las comunidades estudiadas y reducir la vulnerabilidad de dicha actividad. Finalmente, hay que añadir que el valor económico y tradicional son elementos que pueden favorecer al rescate de la meliponicultura en la reserva. 


\section{Bibliografía}

Aguilar, Ingrid, Eduardo Herrera y Gabriel Zamora

2013 "Stingless Bees in Costa Rica", Pot-honey. Legacy of Stingless Bees, pp. 113-124, Patricia Vit, Silvia Pedro y David Roubik (eds.). New York: Springer.

Albores, María, Tania García, Leonardo Durán y Álvaro Aguilar

2011 "Experiencia de la Unión de Cooperativas Tosepan en el fomento de la cría de abejas nativas Pitsilnejmej”, Memorias de VII Seminario Mesoamericano sobre Abejas Nativas, pp. 95-99. Cuetzalan, Puebla: El Colegio de la Frontera Sur y Unión de Cooperativas Tosepan.

Almeida-Muradian, Ligia, Kluas Stramm, Andreia Horita, Ortrud Barth, Alex de Freitas y Letecia Estevinho

2013 "Comparative Study of the Physicochemical and Palynological Characteristics of Honey from Melipona subnitida and Apis mellifera", International Journal of Food Science \& Technology, 48: 1698-1706. DOI: 10.1111/ijfs.12140.

Alves, Rogério

2013 "Production and Marketing of Pot-honey", Pot-honey. A Legacy of Stingless Bees, pp. 541-556, Patricia Vit, Silvia Pedro, David Roubik (eds.). New York: Springer.

Alves, Rogério, Carlos Carvalho, Bruno Souza, Geni Sodré y Luis Marchini

2005 "Características físico-químicas de amostras de mel de Melipona mandacaia Smith (Hymenoptera: Apidae)", Ciência e Tecnologia de Alimentos, 25 (4): 644650. DOI: 10.1590/S0101-20612005000400004.

Ayala, Ricardo, Víctor González y Michael Engel

2013 "Mexican Stingless Bees (Hymenoptera: Apidae): Diversity, Distribution and Indigenous Knowledge", Pot-honey. A Legacy of Stingless Bees, pp. 135-152, Patricia Vit, Silvia Pedro y David Roubik (eds.). New York: Springer.

Barceló, Raquel y David Roubik

2013 "Melipona Bees in the Scientific World: Western Cultural Views", Pot-honey. A Legacy of Stingless Bees, pp. 247-259, Patricia Vit, Silvia Pedro y David Roubik (eds.). Nueva York: Springer.

Cairns, Christine, Rogel Villanueva, Suzanne Koptur y David Bray

2005 "Bee Populations, Forest Disturbance, and Africanization in Mexico", Biotropica, 37 (4): 686-692. DOI: 10.1111/j.1744-7429.2005.00087.x.

Calkins, Charles

1974 "Beekeeping in Yucatan: A Study in Historical-Cultural Zoogeography", Tesis para obtener el grado de doctor en filosofía. Lincoln: The University of Nebraska. 
Carvalho, Carlos, Geni Sodré, Antonio Fonseca, Rogério Alves, Bruno Souza y Lana Clarton 2009 "Physicochemical Characteristics and Sensory Profile of Honey Samples from Stingless Bees (Apidae: Meliponinae) Submitted to a Dehumification Process", Anais da Academia Brasileira de Ciências, 81 (1): 143-149. DOI: 10.1590/ S0001-37652009000100015.

Comisión Nacional de Áreas Naturales Protegidas (CONANP)

2006 Programa de conservación y manejo de la Reserva de la Biósfera Los Petenes. $<$ http://www.conanp.gob.mx/anp/consulta/PCM-petenes.pdf $>$ [consultada el 4 de abril de 2015].

Comisión Nacional del Agua (CNA)

2014 Datos históricos de temperatura y precipitación (1980-2011) de las estaciones meteorológicas de Hecelchakán y Calkiní, Campeche, Comisión Nacional del Agua, Delegación Campeche.

Comisión Nacional para el Conocimiento y Uso de la Biodiversidad (CONABIO) 2000 Uso del suelo y vegetación de la región Los Petenes, Campeche. <http://www. conabio.gob.mx/informacion/gis/layouts/usv_petengw.png > [consultada el 5 de mayo de 2016].

Consejo Nacional de Evaluación de la Política de Desarrollo Social (CONEVAL)

2010 Medición de la pobreza 2010, Porcentaje de población en situación de pobreza, Campeche. <http://www.coneval.org.mx/coordinacion/entidades/Campeche/ Paginas/pob_municipal.aspx > [consultada el 15 de agosto de 2016].

Cortopassi-Laurino, Marilda, Vera Imperatriz, David Roubik, Anne Dollin, Tim Heard, Ingrid Aguilar, Giorgio Venturieri, Connal Eardley y Paolo Nogueira

2006 "Global Meliponiculture: Challenges and Opportunities", Apidologie, 37: 1-18. DOI: https://doi.org/10.1051/apido:2006027.

Crane, Eva

1992 "The Past and Present Status of Beekeeping with Stingless Bees”, Bee World, 73 (1): 29-42. DOI: 10.1080/0005772X.1992.11099110.

Enríquez, María, Carmen Yurrita y M. Dardón

2006 Biología y reproducción de abejas nativas sin aguijón. Guatemala: Universidad de San Carlos de Guatemala y Laboratorio de Entomología Aplicada y Parasitología.

García, Eduardo, Víctor Toledo y Joan Martínez

2008 "Apropiación de la naturaleza por una comunidad maya yucateca: un análisis económico-ecológico", Revista Iberoamericana Economía Ecológica, 7: 27-42.

González, Jorge

2008 Cría y manejo de abejas nativas sin aguijón en México. Mérida: Planeta Impresores. 
González, Jorge y José Quezada

2011 "Producción tradicional de miel: abejas nativas sin agujón (trigonas y meliponas)”, Biodiversidad y Desarrollo Humano en Yucatán, pp. 382-384, R. Durán y M. Méndez (eds.). Mérida: Centro de Investigación Científica de Yucatán, Programa de Pequeñas Donaciones del Fondo para el Medio Ambiente Mundial, Comisión Nacional para el Conocimiento y Uso de la Biodiversidad y Secretaría de Desarrollo Urbano y Medio Ambiente.

González, Jorge, José Quezada y Luis Medina

2006 "New Perspectives for Stingless Beekeeping in the Yucatan: Results of an Integral Program to Rescue and Promote the Activity", Journal of Apiculture Research, 45 (4): 234-239. DOI: 10.1080/00218839.2006.11101356.

Güiemes, Francisco, Rogel Villanueva y Karen Eaton

2003 "Honey Production by the Mayans in the Yucatan Peninsula", Bee World, 84: 144-154. DOI: 10.1080/0005772X.2003.11099596.

Halcroft, Megan, Robert Spooner y Anne Dollin

2013 “Australian Stingless Bees”, Pot-honey. A Legacy of Stingless Bees, pp. 35-72, Patricia Vit, Silvia Pedro y David Roubik (eds.). New York: Springer.

Hernández Xolocotzi, Efraím, Samuel Levy Tacher y Eduardo Bello

1995 “La Roza-Tumba-Quema en Yucatán”, La milpa en Yucatán, Tomo I: 35-85, Efraím Hernández Xolocotzi, Eduardo Bello y Samuel Levy Tacher (eds.). Montecillos: Colegio de Postgraduados.

Instituto Nacional de Estadística y Geografía (INEGI)

2010 Censo de población y vivienda 2010. Principales resultados por localidad, Campeche. <http://www.inegi.org.mx/est/contenidos/proyectos/ccpv/cpv2010/ iter_2010.aspx> [consultada el 13 noviembre del 2017].

Jones, Richard

2013 "Stingless Bees: A Historical Perspective", Pot-honey. A Legacy of Stingless Bees, pp. 219-227, Patricia Vit, Silvia Pedro y David Roubik (eds.). New York: Springer.

Kawulich, Barbara

2005 “Participant Observation as a Data Collection Method”, Forum: Qualitative Social Research, 6 (2), art. 43. <http://www.qualitative-research.net/index.php/ fqs/article/view/466/998 > [consultada el 10 de abril de 2015].

Lage, Lorena, Livia Coelho, Helder Resende, Mara Tavares, Lucio Campos y Tânia Fernandes -Salomâo

2012 "Honey Physicochemical Properties of Three Species of the Brazilian Melipona”, Anais Academia Brasileira de Ciências, 84 (3): 605-608. DOI: 10.1590/ S0001-37652012005000051. 
Meléndez, Virginia, Laura Meneses y Peter Kevan

2013 "Effects of Human Disturbance and Habitat Fragmentation on Stingless Bees”, Pot-honey. A Legacy of Stingless Bees, pp. 269-282, Patricia Vit, Silvia Pedro y David Roubik (eds.). New York: Springer.

Nárez, Jesús

1988 "Algunos datos sobre las abejas en la época prehispánica”, Revista Mexicana de Estudios Antropológicos, 33 (1): 123-140.

Ocampo, Genoveva

2013 "Medicinal Uses of Melipona beecheii Honey, by the Ancient Maya", Pot-honey. A Legacy of Stingless Bees, pp. 229-240, Patricia Vit, Silvia Pedro y David Roubik (eds.). New York: Springer.

Oliveira, Anna, Giorgio Venturieri y Felipe Contrera

2013 "Body Size Variation, Abundance and Control Techniques of Pseudohypocera kerteszi, a Plague of Stingless Bee Keeping”, Bulletin of Insectology, 66 (2): 203-208.

Palma, David, Joel Zavala, Francisco Bautista, Marco Morales, Antonio López, Edgar Shirma y José Gallegos

2012 Estudio sobre el plan de uso sustentable de los suelos del estado de Campeche, Informe Técnico. Campeche: Colegio de Postgraduados y Secretaria de Desarrollo Rural de Campeche.

Pat, Lucio, José Nahed, Manuel Parra, Austreberta Nazar, Luis García, Eduardo Bello y Obiermar Herrera

2008 "Modos de vida y seguridad alimentaria de los mayas de Campeche", Memoria Concurso redsan-fao, pp. 128-168, Rodrigo Rivera y Paola Valle (eds.). Santiago de Chile: fao.

Pat, Lucio, José Nahed, Manuel Parra, Luis García, Austreberta Nazar y Eduardo Bello

2010 "Impacto de las estrategias de ingresos sobre la seguridad alimentaria en comunidades mayas del norte de Campeche", Archivos Latinoamericanos de Nutrición, 60 (1): 48-55.

Pat, Lucio, Pablo Hernández, Juan Pat y Francisco Guízar

2016 Situación actual y perspectivas de la meliponicultura en comunidades aledañas a la reserva de la biósfera Los Petenes, Campeche. Informe final del estudio técnico. $<$ http://aleph.ecosur.mx:8991/exlibris/aleph/a22_1/apache_media/J2LCGGQYPLHXEQ1CDSR386KPLC31LB.pdf> [consultada el 10 de julio de 2017].

Quezada, José y Jorge González

1994 "A Preliminary study on the Development of Colonies of Melipona beecheii in Traditional and Rational Hives", Journal of Apicultural Research, 33 (3): 167170. DOI: 10.1080/00218839.1994.11100865. 
Quezada, José, William May y Jorge González

2001 "Meliponiculture in Mexico: Problems and Perspective for the Development", Bee World, 82 (4): 160-167. DOI: 10.1080/0005772X.2001.11099523.

Ramos Pedro, Manuel Parra, Javier Fortanelli y Miguel Aguilar

2016 "El linaje K’ulub cambia de estrategia. Diversificación productiva en la zona cafetalera de Oxchuc, Chiapas”, Agricultura, Sociedad y Desarrollo, 13: 277301.

Rello, Fernando

2001 Instituciones y pobreza rurales en México y Centroamérica. Santiago de Chile: Comisión Económica para América Latina y el Caribe (Estudios y Perspectivas, 2).

Robles, Bernardo

2011 "La entrevista a profundidad: una técnica útil del campo antropofísico", Cuicuilco, 18 (52): 39-49.

Rosales, Margarita y Amada Rubio

2010 "Apicultura y organizaciones de apicultores entre los mayas de Yucatán", Estudios Cultura Maya, XXXV: 163-186. DOI: 10.19130/iifl.ecm.2010.35.27.

Ruano, Carlos

2007 “Ácido acético como atrayente de fóridos (Díptera: Phoridae)", Revista de Protección Vegetal, 13 (2): 1-8.

Souza, Bruno, David Roubik, Ortrud Barth, Tim Heard, Eunice Enríquez, Carlos Carvalho, Jerônimo Villas-Bôas, Luis Marchini, Jean Locatelli, Livia Persano-Oddo, Ligia Almeida-Muradian, Stefan Bogdanov and Patricia Vit

2006 "Composition of Stingless Bee Honey: Setting Quality Standards”, Interciencia, 31 (12): 867-875.

Terán, Silvia y Christian Rasmussen

1994 La milpa de los mayas. Mérida: Ministerio de Relaciones Exteriores de Dinamarca.

Toledo, Víctor, Narciso Barrera, Eduardo García y Pablo Alarcón

2008 "Uso múltiple y biodiversidad entre los mayas yucatecos (México)", Interciencia, 33 (5): 345-352.

Villanueva, Rogel

2015 "La meliponicultura en la zona maya de Quintana Roo", Manejo de las abejas sin aguijón en Mesoamérica, pp. 35-46, Miguel Guzmán y Rémy Vandame (coords.). San Cristóbal de las Casas: El Colegio de la Frontera Sur.

Villanueva, Rogel, David Roubik y Wilberto Colli

2005 "Extinction of Melipona beecheii and Traditional Beekeeping in the Yucatan Peninsula”, Bee World, 86 (2): 35-41. DOI: 10.1080/0005772X.2005.11099651. 
Vit, Patricia

2008 "Valorización de la miel de abejas sin aguijón (Meliponini)", Revista de la Facultad de Farmacia, 50 (2): 20-28.

Vit, Patricia, Margarita Medina y María Enríquez

2004

"Quality Standards for Medicinal Uses of Meliponinae Honey in

Guatemala, Mexico and Venezuela”, Bee World, 81 (1): 2-5. DOI: 10.1080/0005772X.2004.11099603.

Zralka, Jaroslaw, Wieslaw Koszkul, Katarzyna Radnicka, Laura Sotelo y Bernard Hermes

2014 "Excavations in Nakum Structure 99: New Data on Protoclassic Rituals and Lumbian Maya Beekeeping”, Estudios de Cultura Maya, 44 (2): 85-117. DOI: 10.19130/iifl.ecm.2014.44.790. 